\title{
Evaluation of the erythrocyte-UFA (E-UFA) mobility test for the diagnosis of multiple sclerosis
}

\author{
J CUYPERS AND H REDDEMANN
}

From the Department of Neurology, Klinikum Steglitz, Berlin, West Germany

SUMMARY The absolute electrophoretic mobility of red blood cells was examined before and after the addition of linoleic acid. The determinations were performed with a Zeiss cytopherometer. The blood was taken from 22 patients with multiple sclerosis in different phases of their disease. A group of 17 patients with other neurological diseases and three apparently healthy subjects served as controls. Our results show that the mobility of red blood cells was either accelerated or inhibited in the presence of linoleic acid, both in the multiple sclerosis patients as well as in the control group. The increase or inhibition of the absolute mobility was small and randomly distributed. The value of this so-called E-UFA test (erythrocyte-unsaturated fatty acid) as a specific diagnostic test for multiple sclerosis is not confirmed by our results.

A precise diagnosis of multiple sclerosis would be of great importance for research and clinical management, for at present it is a matter of probability and exclusion. Recently Field et $a^{1}$ claimed to have found a diagnostic test for multiple sclerosis which was said to be valid in each phase of the disease and extremely specific. In this test the electrophoretic mobility of erythrocytes of patients with multiple sclerosis (MS) is inhibited in the presence of linoleic acid. The test is based on results which indicate an anomaly of fatty acid metabolism producing changes both in myelin composition and in the lipid structure of other cells, for instance red blood cells. ${ }^{2-5}$ Reported results on the value of this so-called E-UFA (erythrocyte-unsaturated fatty acid) test have been controversial. ${ }^{6-9} \mathrm{We}$ therefore examined this particular test and the following paper describes our experiences and results.

\section{Material and method:}

Fresh red blood cells (RBC) were prepared from 20 MS patients in different stages of the disease. Only those patients who could be judged as definite, using the criteria of McAlpine, were selected. ${ }^{10}$ Three apparently healthy persons and 19 patients with other neurological disorders (OND) (cerebrovascular

Address for reprint requests: Dr med Jochen Cuypers, Department of Neurology, Klinikum Steglitz of the Free University of Berlin, Hindenburgdamm 30, D 1000 Berlin 45, West Germany.

Accepted 16 July 1980 accidents, Parkinsonism, brain tumor, lumbar disc prolapse and heredity ataxia) served as controls. All subjects, who agreed to participate in the test, told us they did not use a diet containing a high quantity of polyunsaturated fatty acids.

The method used was essentially the same as described by Field. ${ }^{1}$ Red blood cells were prepared by defibrination of $15 \mathrm{ml}$ of fresh blood with glass beads under sterile conditions. The further procedure was carried out in tubes and pipettes highly purified for one day in $\mathrm{n}-\mathrm{HCl}$ and bidistilled water, but not sterilised; sterilisation did not prove to be of any importance in preliminary experiments. The red cells were washed three times in sterile $0.9 \%$ saline and then once in Hanks Medium 199 and centrifuged at $400 \mathrm{~g}$ after each step. Finally they were suspended in this medium at a concentration of $2.8 \times 10^{7}$ cells $/ \mathrm{ml}$ and processed immediately.

The absolute electrophoretic mobility was measured in a Zeiss cytopherometer. The current used was $7.4 \mathrm{~mA}$. The time which one erythrocyte needed for going ahead and back one field in the ocular measuring grid $(=32 \mu)$ was measured with a stopwatch. Forty cells were measured in each blood suspension, and the mean value and standard deviation were calculated. A measurement was only performed when there was vertical sedimentation of erythrocytes. This was often difficult and sometimes impossible, especially in the beginning. The reason for this "drift" is unknown. The absolute mobility was calculated by the following formula:

$$
\text { mobility }=\text { speed } / \text { field strength }=\frac{3136}{\mathrm{t} \times 7.4 \times \rho}
$$

( $\mathrm{t}=$ time in seconds to move $32 \mu, \rho=$ specific resistance of the medium). 
The specific resistance of our medium was determined in the conductolyser and had a value of about $70( \pm 2) \Omega$ per $\mathrm{cm}$. The determinations were carried out blindly, that is the examiner did not know whose blood he was processing. After determining the mobility of the erythrocytes without linoleic acid, a consecutive redetermination was done by adding $20 \mu \mathrm{l}$ (equivalent to $0.16 \mathrm{~g} / \mathrm{l}$ ) of highly purified linoleic acid to the erythrocyte suspension. We chose this concentration on the basis of a suggestion made by Field, who told us that the higher concentration would bring better results. The temperature of the measuring chamber remained constant at $25^{\circ} \mathrm{C}$.

In the second half of the experiments, detergents (Tween 80, Triton) were added to the suspension in order to improve the solubility of linoleic acid. In those cases determinations were performed (or the attempt was made to do so) with and without detergents.

\section{Results}

\section{MS Patients}

The values of each patient blood either with or without linoleic acid (LA) are shown in table 1 . The addition of LA led to rather irregularpositive or negative-deviations ( $p$ not significant using the Wilcoxon test). The range was from -9.94 to $+6.78 \%$ with a mean value of $-0.92 \%$.

Most determinations were performed two or

Table 1 MS patients without linoleic acid (= control) and with linoleic acid: mean value and $S D$ of the absolute mobility of red blood cells $(\mu / s / V / c m)$

\begin{tabular}{|c|c|c|c|c|}
\hline \multirow[t]{2}{*}{$\begin{array}{l}\text { Pat } \\
\text { number }\end{array}$} & \multicolumn{2}{|c|}{$\begin{array}{l}\text { Absolute } \\
\text { mobility } \\
\text { in } \mu / \mathrm{s} / \mathrm{V} / \mathrm{cm}\end{array}$} & \multirow{2}{*}{$\begin{array}{l}\text { Change in } \\
\text { absolute } \\
\text { mobility } \\
\text { in } \%\end{array}$} & \multirow{2}{*}{ Remarks } \\
\hline & Control & $\begin{array}{l}\text { Linoleic } \\
\text { acid }\end{array}$ & & \\
\hline 1 & $0.822(0.032)$ & $0.775(0.038)$ & -5.72 & Stable MS \\
\hline 3 & $0.784(0.030)$ & $0.818(0.047)$ & $+4 \cdot 34$ & Acute MS \\
\hline 4 & $0.805(0.039)$ & $0.725(0.029)$ & -9.94 & Acute MS \\
\hline 5 & $0.740(0.035)$ & $0.734(0.038)$ & -0.81 & Stable MS \\
\hline 6 & $0.735(0.038)$ & $0.741(0.036)$ & +0.82 & Acute MS \\
\hline 7 & $0.735(0.036)$ & $0.706(0.031)$ & -3.95 & Stable MS \\
\hline 8 & $0.734(0.042)$ & $0.722(0.032)$ & $-1 \cdot 6$ & Stable MS \\
\hline 9 & $0.728(0.036)$ & $0.763(0.031)$ & $+4 \cdot 8$ & Chron prog MS \\
\hline 10 & $0.791(0.037)$ & $0.771(0.045)$ & $-2 \cdot 5$ & Acute MS \\
\hline 14 & $0.804(0.047)$ & $0.791(0.038)$ & $-1 \cdot 6$ & Acute MS \\
\hline 15 & $0.756(0.040)$ & $0.734(0.037)$ & $-2 \cdot 9$ & Stable MS \\
\hline 16 & $0.761(0.040)$ & $0.719(0.038)$ & $-5 \cdot 52$ & Stable MS \\
\hline 19 & $0.724(0.033)$ & $0.762(0.035)$ & $+5 \cdot 2$ & Stable MS \\
\hline 20 & $0.756(0.030)$ & $0.747(0.040)$ & $-1 \cdot 2$ & Chron prog MS \\
\hline 22 & $0.758(0.042)$ & $0.738(0.041)$ & $-2 \cdot 6$ & Stable MS \\
\hline 23 & $0.783(0.031)$ & $0.750(0.029)$ & $-4 \cdot 21$ & Stable MS \\
\hline 26 & $0.865(0.046)$ & $0.868(0.042)$ & +0.35 & Chron. MS \\
\hline 27 & $0.797(0.035)$ & $0.870(0.049)$ & +1.63 & Chron. MS \\
\hline 29 & $0.794(0.031)$ & $0.768(0.031)$ & $-3 \cdot 27$ & Acute MS \\
\hline 37 & $0.767(0.046)$ & $0.819(0.054)$ & $+6 \cdot 78$ & Acute MS \\
\hline 40 & $0.785(0.047)$ & $0.786(0.031)$ & +0.13 & Acute MS \\
\hline 43 & $0.787(0.034)$ & $0.798(0.038)$ & $+1 \cdot 38$ & Acute MS \\
\hline
\end{tabular}

Table 2 Patients with other neurological diseases and healthy subjects without linoleic acid (= control) and with linoleic acid: mean value and $S D$ of the absolute mobility of red blood cells $(\mu / \mathrm{s} / \mathrm{V} / \mathrm{cm})$

\begin{tabular}{|c|c|c|c|c|}
\hline \multirow[t]{2}{*}{$\begin{array}{l}\text { Pat } \\
\text { number }\end{array}$} & \multicolumn{2}{|c|}{$\begin{array}{l}\text { Absolute } \\
\text { mobility } \\
\text { in } \mu / \mathrm{s} / \mathrm{V} / \mathrm{cm}\end{array}$} & \multirow{2}{*}{$\begin{array}{l}\text { Change in } \\
\text { absolute } \\
\text { mobility } \\
\text { in } \%\end{array}$} & \multirow[t]{2}{*}{ Remarks } \\
\hline & Control & $\begin{array}{l}\text { Linoleic } \\
\text { acid }\end{array}$ & & \\
\hline 2 & $0.794(0.023)$ & $0.791(0.023)$ & -0.38 & Polyneuropathy \\
\hline 11 & $0.741(0.039)$ & $0.734(0.037)$ & -0.94 & Cer ischaemia \\
\hline 12 & $0.778(0.049)$ & $0.755(0.036)$ & $-3 \cdot 0$ & Parkinsonism \\
\hline 13 & $0.724(0.026)$ & $0.759(0.039)$ & $+4 \cdot 8$ & Stroke \\
\hline 21 & $0.746(0.033)$ & $0.744(0.030)$ & -0.27 & Epilepsy \\
\hline 24 & $0.834(0.046)$ & $0.858(0.039)$ & $+2 \cdot 88$ & $\begin{array}{l}\text { Arteriitis } \\
\text { cranialis }\end{array}$ \\
\hline 28 & $0.774(0.034)$ & $0.767(0.034)$ & -0.9 & Stroke \\
\hline 30 & $0.751(0.030)$ & $0.759(0.041)$ & $+1 \cdot 07$ & Crohn's disease \\
\hline 34 & $0.871(0.040)$ & $0.844(0.052)$ & $-3 \cdot 10$ & Parkinsonism \\
\hline 35 & $1.012(0.055)$ & $0.905(0.056)$ & $-10 \cdot 5$ & Cer vasc disease \\
\hline 36 & $0.967(0.063)$ & $0.924(0.048)$ & $-4 \cdot 45$ & Stroke \\
\hline 38 & $0.771(0.038)$ & $0.738(0.033)$ & $-4 \cdot 28$ & Parkinsonism \\
\hline 39 & $0.820(0.046)$ & $0.772(0.033)$ & $-5 \cdot 85$ & Parkinsonism \\
\hline 41 & $0.761(0.040)$ & $0.778(0.041)$ & $+2 \cdot 23$ & Parkinsonism \\
\hline 42 & $0.808(0.034)$ & $0.829(0.047)$ & $+2 \cdot 60$ & Parkinsonism \\
\hline 17 & $0.790(0.041)$ & $0.766(0.040)$ & -3.03 & Healthy \\
\hline 18 & $0.783(0.043)$ & $0.761(0.036)$ & $-2 \cdot 80$ & Healthy \\
\hline 33 & $0.885(0.055)$ & $0.804(0.050)$ & $-9 \cdot 15$ & Healthy \\
\hline 44 & $0.830(0.042)$ & $0.792(0.040)$ & $-4 \cdot 80$ & $\begin{array}{l}\text { Friedreich's } \\
\text { ataxia }\end{array}$ \\
\hline 45 & $0.817(0.043)$ & $0.765(0.038)$ & $-6 \cdot 80$ & $\begin{array}{l}\text { Heriditary } \\
\text { ataxia }\end{array}$ \\
\hline
\end{tabular}

three times, either the same day or one day later. These values (which are not mentioned in the tables) revealed the same tendency, that is the deviation remained positive or negative. In some cases, however, it changed. Detailed analysis of the values showed no correlation to certain stages or subtypes (acute or stable, relapsing or chronic).

2 Control group (normal persons and patients with other neurological disorders)

The values are shown in table 2 . LA produced an acceleration in five of 20 cases and an inhibition of the absolute mobility in the remaining cases $(p=$ significant at the $5 \%$ level using the Wilcoxon test). The range of this deviation was from -10.5 to +4.8 with a mean value of $-2.33 \%$. The last two patients in table 2 suffered from a hereditary ataxia (Friedreich's ataxia and Marie's ataxia). Anomalies of erythrocytes have also been reported in these patients. ${ }^{11}$ The inhibition found in these two patients was in the same range as the other cases. When comparing the relative deviations produced by LA in the two groups it can be seen that 11 of 22 cases in the MS group and 15 of 20 cases in the control group showed an inhibition of the absolute mobility. Using the Wilcoxon test, this difference 
was significant at the $5 \%$ level, but the tendency was just the opposite of what was expected.

\section{Discussion}

The E-UFA test is based on a variety of observations which indicate an involvement of fatty acids and especially of polyunsaturated fatty acids (PUFA) in multiple sclerosis. ${ }^{2-5}{ }^{12-15}$ Agranoff and voldoerg ${ }^{3}$ and Galli $^{2}$ showed that denciency of PUFA in food led to permanent changes in myelin composition, which in turn could result in reduced resistance to a pathogenic factor. Other authors, ${ }^{12}$ proposed an inborn error of fatty acid metabolism in MS patients. Gul, ${ }^{4}$ Tsang $^{5}$ found a significant decrease of PUFA in phospholipids of erythrocytes, platelets and lymphocyte membranes in MS patients. There are also several reports of a decreased level of PUFAs in MS blood, ${ }^{15}$ normal levels, however, could also be shown. ${ }^{16}$ The findings of Love, ${ }^{17}$ who observed a decrease in PUFA blood concentrations in patients with acute nonneurological diseases, indicate that this may be an unspecific effect.

These results, the validity of which cannot be discussed here, were attractive in suggesting a predisposing factor which might possibly be treated. They led to therapeutic trials with lineoleic acids. ${ }^{18-20}$ The results, however, were disappointing as they showed no or only a slight beneficial effect of long-term intake of LA on the course of the disease. This PUFA deficiency was also used as a diagnostic test and first reports were very encouraging. Our own results, however, with the E-UFA test, in agreement with those of others ${ }^{7} 8$ do not favour this procedure in the diagnosis of MS. The percentage deviations in form of an acceleration or deceleration of the erythrocyte in the electrical field were small and insignificant. They were irregular, rather randomly distributed and in a range considered by experienced groups to be normal for this method. We could not even see a tendency for erythrocytes to decelerate in MS patients or to accelerate in controls; indeed, the results tended the opposite way.

Because our primary aim was to examine the validity of the method we dispensed with the use of archidonic acid and oleic acid. Another reason was that, according to Field, these two fatty acids rapidly haemolysed the erythrocytes; determinations of the mobility thus becoming difficult. In our results the absolute mobility of the erythrocytes (at a current strength of $7.4 \mathrm{~mA}$ ) was approximately $20-30 \%$ lower than that usually described in the literature. ${ }^{21}$ A technical examination of our cytopherometer did not show any defect, so that we do not know the reason for this lower value. The absolute mobility of the erythrocytes was in the same range in all determinations throughout the entire experimental period. The standard deviation was still lower than that reported in the literature. This shows that the cytopherometer did function accurately. We also determined whether a higher absolute mobility, approximately in the range of that reported in the literature (= about $1 \cdot 1$ $\mathrm{mA} / \mathrm{U} / \mathrm{s}$ ) had any influence on our results. At first we measured the absolute mobility of the erythrocytes on our cytopherometer at such a high current strength $(\sim 9 \mathrm{~mA})$ that it increased to about $1 \cdot 1 \mathrm{~mA} / \mathrm{U} / \mathrm{s}$. The values did not show any alterations compared to those obtained at the lower absolute mobility. Furthermore, we made determinations on another cytopherometer (kindly put at our disposal by $\mathrm{Dr}$ Weinhold, Bundesgesundheitsamt Berlin). Here the absolute mobility actually did reach values of $1 \cdot 1$ $\mathrm{mA} / \mathrm{U} / \mathrm{s}$ at a current strength of $7.4 \mathrm{~mA}$. After addition of linoleic acid to the erythrocyte suspension the same irregular and slight deviations could be seen as with our apparatus. From this we conclude that the absolute mobility - at least in the range we observed-had no influence on the test results.

Linoleic acid was rapidly and apparently completely dissolved in absolute alcohol. However, on adding this solution to the erythrocyte suspension linoleic acid appeared in the form of droplets on the surface of the watery solution. Determinations with $\mathrm{C}_{14}$-LA showed that LA was, at the concentration used, only dissolved to $10 \%$ in the watery erythrocyte suspension. We do not know if this low solubility had any influence on the results. The use of other solvents (for example acetone) gave rise to difficulties because of the rapid haemolysis of the erythrocyte. Therefore we tried to improve the solubility of linoleic acid by the addition of detergents. But even the use of detergents which should not lead to haemolysis, regularly did so. Finally we would emphasise that the use of the cytopherometer is often marred by rather "capricious quirks" of the apparatus. Reproducible results can only be obtained by a long training period and very exact handling.

\section{References}

1 Field GJ, Joyce G, Smith BM. ErythrocyteUFA (Eufa) mobility test for multiple sclerosis: 
Implications for pathogenesis and handling of the disease. J Neurol 1977; 214:113-27.

2 Galli C, White HB Jr, Paoletti R. Brain lipid modifications induced by essential fatty acid deficiency in growing male and female rats. $J$ Neurochem 1970; 17:347-55.

3 Agranoff BW, Goldberg D. Diet and the geographical distribution of multiple sclerosis. Lancet 1974; 2:1061-6.

4 Gul S, Smith AD, Thompson RHS, Wright H, Payling, Zilkha KJ. Fatty acid composition of phospholipids from platelets and erythrocytes in multiple sclerosis. J Neurol Neurosurg Psychiatry 1970; 33:506-10.

5 Tsang WM, Belin J, Monro JA, Smith AD, Thompson RHS, Zilkha KJ. Relation between plasma and lymphocyte linoleate in multiple sclerosis. J Neurol Neurosurg Psychiatry 1976; 39:767-771.

6 Seaman GVF, Swank RL, Tamblyn ChM, Zukoski ChF. IV: Simplified red-cell electrophoretic mobility test for multiple sclerosis. Lancet 1979; 1138-9.

7 Hawkins SA, Millar JHD. Erythrocyte electrophoretic mobility test for multiple sclerosis. Lancet 1979; 165-6.

8 Stoof JC, Vrijmoed-de Vries MC, Koetsier JC, Langevoort HL. Evaluation of the red blood cell cytopherometric test for the diagnosis of multiple sclerosis. Acta Neurol Scand 1977; 56:170-6.

9 Zibetti A, Bisaccia C, Caputo D. E-UFA laboratory test for $M S$. Abstracts, 11th World Congress of Neurology, Amsterdam. Amsterdam/Oxford: Excerpta Medica, 1977: 265.

10 McAlpine D, Lumsden ChE, Acheson ED. Multiple Sclerosis. Edinburgh: Livingstone, 1972.
11 Draper P, Huang YS, Shapcott D et al. Erythrocyte membrane lipids in Friedreich's Ataxia. Canad J Neurol Sci 1979; 6:291-4.

12 Thompson RHS. A biochemical approach to the problem of multiple sclerosis. Proc $R$ Soc Med 1976; 59:269-76.

13 Mertin J, Meade CJ. Relevance of fatty acid in multiple sclerosis. Br Med Bull 1977; 33:67-71.

14 Davison AN, Cuzner ML. Immunochemistry and biochemistry of Myelin. Br Med Bull 1977; 33: 60-6.

15 Belin J, Petter N, Thompson RHS, Zilkha KJ. Linoleate metabolism in multiple sclerosis. $J$ Neurol Neurosurg Psychiatry 1971; 34:25-9.

16 Shukla VKS, Clausen J. Linoleate and fatty acid pattern of serum lipids in multiple sclerosis. Acta Neurol Scand 1978; 57:270-4.

17 Love WC, Cashell A, Reynolds M, Callaghan N. Linoleate and fatty acid pattern of serum lipids in multiple sclerosis and other diseases. $\mathrm{Br} \mathrm{Med} \mathrm{J}$ 1974; 3:18-21.

18 Paty DW, Cousin HK, Read S, Adlakha K. Linoleic acid in multiple sclerosis: failure to show any therapeutic benefit. Acta Neurol Scand 1978; 58:53-8.

19 Millar JHD, Zilkha KJ, Langman JJS et al. Double blind trial of linoleates supplementation of the diet in multiple sclerosis. Br Med J 1973; 3:765.

20 Bates D, Fawcett PRW, Shaw DA, Weightman D. Polyunsaturated fatty acids in treatment of acute remitting multiple sclerosis. $\mathrm{Br}$ Med J 1978; 2:1390-1.

21 Vransky VK. Die Zellelektrophorese. In: Fortschritte der experimentellen und theoretischen Biophysik, Bd 18, Leipzig, 1974. 